\title{
Wittgenstein's Ethical Individualism as a Foundation for Environmental Ethics
}

\author{
Peter Takov1, Voltaire Djia ${ }^{2}$ \\ ${ }^{1}$ Catholic University of Cameroon, Bamenda, Cameroon \\ ${ }^{2}$ University of Yaounde I, Yaounde, Cameroon \\ Email: petakov65@yahoo.co.uk,djiaprof@gmail.com
}

How to cite this paper: Takov, P., \& Djia, V. (2020). Wittgenstein's Ethical Individualism as a Foundation for Environmental Ethics. Open Journal of Philosophy, 10, 427442.

https://doi.org/10.4236/ojpp.2020.104030

Received: August 22, 2020

Accepted: November 3, 2020

Published: November 6, 2020

Copyright $\odot 2020$ by author(s) and Scientific Research Publishing Inc. This work is licensed under the Creative Commons Attribution International License (CC BY 4.0).

http://creativecommons.org/licenses/by/4.0/

cC) (i) Open Access

\begin{abstract}
Caring for the environment has most often taken the form of summits. The idea behind summits is that environmental affairs are global, calling for collective responsibility as well as for collective action. In this connection, responsibilities have generally been shared among the various member countries. This is in a bid to reduce the level of pollution and save our mother earth. In this work, we propose an alternative way of acting, which is an interpretation of Wittgenstein's ethical views which rely mostly on transforming our view of who we are and how we relate to the world. Our view runs against what we could call the "collective action paradigm" which usually ends in tu quoque suspicion among the different stakeholders. When the "save the world task" is shared among countries, they become suspicious of each other, in such a way that a small violation of the agreement by one country is considered as a good reason for others to do the same. In this suspicion game, that sometimes takes other forms, the real battle, saving the world, is completely forgotten. The ethical views of Wittgenstein that we reconstruct here have two central elements, the rejection of psychological subjectivity and the rejection of pragmatism in ethical affairs that both consider nature as an instrument. Our final aim is to show that if we consider the most important question of life-what is the meaning of life?-and give an appropriate answer to it, then we can put an end to "the darkness of our time", which consists in thinking that everything, including nature, can be subjected to our domination.
\end{abstract}

\section{Keywords}

Environment, Individualism, Collective Action, Intrinsic Value, Environmental Education

\footnotetext{
${ }^{1}$ The expression is used by Wittgenstein in the preface of the Philosophical Investigations to describe the predominant view of the contemporary era that man, through science and technology, is said to be at the top of the world.
} 


\section{Introduction}

Last September 23, 2019, another climate summit was held in New York (USA) to answer an old question: how to respond to the Impending Environmental Crisis? The main objective of the summit was clear: to see how the Paris agreements could be saved. Few weeks after the New York summit $\left(5^{\text {th }}\right.$ November 2019), this is what Stephen Leahy published on the National geographic website (www.nationalgeographic.com): "The majority of the carbon emission reduction pledges for 2030 that 184 countries made under the Paris Agreement aren't nearly enough to keep global warming well below 3.6 degrees Fahrenheit ( 2 degrees Celsius). Some countries won't achieve their pledges, and some of the world's largest carbon emitters will continue to increase their emissions, according to a panel of world-class climate scientists." In fact, many countries have not been honouring their engagements taken during the Paris climate summit in 2015. Four years later then, and even more than that, problems subsist. This shows how it is difficult to find a real collective response to environmental crises. Are these failures of collective responses in addressing environmental crises not an opportunity to consider other options? Can the individual response to environmental crises be a reliable alternative? This work seeks to provide an affirmative answer to this last question. We will be arguing here for a global individualism. We will show that the "collective action paradigm" as it now exists, cannot tackle the problem of environmental crises. Because this collective action paradigm is exposed to the problems of collective actions, the appeal to individual action is a better option. We will try to see the specific form that this individual action can take, following Wittgenstein's configuration of the relationship of the individual to the world. The paper is divided into three main sections. In the first section, we conduct a brief literature review. In the second, we examine the collective action approach and outline some of its shortcomings. These shortcomings will permit us to propose in the second section the individual action approach as it can be reconstructed from Wittgenstein's ethics and show that it is worth considering in the present critical situation.

\section{Brief Literature Review}

As the global response to climate crisis proves inefficient (see introduction above), recent theorists have started considering the individual as a possible response to environmental crisis. This appeal to the individual, as Peeters suggests, is quite recent (Peeters, 2015). It is one of such individualistic approaches that we seek to construct, based on Wittgenstein's moral philosophy. Wittgenstein's moral philosophy has regained interest in recent literature, extending to some previously unexplored domains. To take some cases, Michael Peters has tried to link Wittgenstein's ethics to the question of suicide (Peters, 2020) and Søndergaard Christensen has explored the link between Wittgenstein's ethics and virtue ethics (Søndergaard Christensen, 2019).

However, the connection between Wittgenstein's ethics and the question of 
environmental philosophy has rarely been explored. Among other attempts, Sarratt Nicholas M. defended a Master of Arts thesis titled "Ecological Forms of Life: Wittgenstein and Ecolinguistics" (Sarratt, 2012) in which he showed that Wittgenstein's later work in the Philosophical Investigations could be interpreted in the light of ecolinguistics. Ecolinguistics has two main branches. On the one hand, it uses an ecological metaphor to describe the workings of language. In 1972, for instance, Einer Haugen launched this approach by writing "The ecology of language" in which he presented linguistics as "the study of interactions between any given language and its environment," where "environment" is not understood to mean the "physical" world of objects broadly construed, but rather in the cultural sense of the word: "The true environment of a language is the society that uses it as one if its codes. Language exists only in the minds of its users, and it only functions in relating these users to one another and to nature, i.e. their social and natural environment" (Sarratt, 2012: p. 6). On the other hand, the word "ecology" is used in its biological (as opposed to metaphorical) sense and the role of language as an aggravating factor of, and possible solution to, environmental problems (Sarratt, 2012: p. 17), given that language influences how we perceive and act in a biophysical environment. In 1991 for instance, Wilhelm Trampe outlined this approach by underlining the fact that "a linguistics based firmly on the interrelationships between humans and the environment, as expressed through language and communication, will create insights which will above all show languages as life forms (Sarratt, 2012: p. 18).” It is mainly in this second branch that Wittgenstein intervenes.

More recently, Taylor has defended the "common life" interpretation of Wittgenstein's ethics, especially as it is formulated in his Philosophical Investigations (Taylor, 2019). According to this interpretation, our moral responses to other human beings and animals, and the kind of moral claims they might make on us, are not dependent on their possession of various isolable properties or capacities that might justify those responses and claims. For instance, "when I describe how I am riveted for a moment on the struggle of an injured bird outside my window to get up on a wall, nothing in what I say about my response to this bird, my concern for it, assumes it was justified by some view about the cognitive capacities of birds." (p. 220) Rather, my response, Taylor suggests, "express[es] my engagement with other creaturely life, an aspect of my fellowship with creatures, which you might both comprehend and come to share in" (Id.). As Taylor concludes, "the kind of shared natural responsiveness to creaturely life indicated previously, and which gives expression to our fellowship, on the one hand, with animals, and on the other, with human beings, provides the background against which we have reason to do, believe and more broadly to say specific things in everyday commerce with other human beings and animals in the first place" (Id.).

Lastly, Campagna and Guevara (Campagna \& Guevara, 2020) have recently followed Sarratt's line of interpretation by proposing to use the concept of "form of life" to capture the different facts related to climate change. The concept of 
"form of life", they suggest, gives us a standard set that will permit us to put together the different languages used to describe climate change.

As we can notice, the relation between Wittgenstein's ethics and the issue of environmental philosophy is still under construction. We hope that this work will add something to the efforts done by other researchers.

\section{The Collective Action Approach to Environmental Crises and Its Pitfalls}

In this second part, our attention is focused on the main form of collective action response to the environmental crises, viz, the global governance response. The global governance response suggests that environmental issues be handled by a form of multistate organization that will plan and give norms to be followed at micro-levels or by local communities. This is mainly applied through the concepts of mitigation and adaptation.

\subsection{The Concept of Global Governance Explained}

The global governance option in environmental issues provides a negative answer to the following question: Can a fragmented and often highly conflictual political system made up of over 170 sovereign states and numerous other actors achieve the high (and historically unprecedented) levels of co-operation and policy coordination needed to manage environmental problems on a global scale? (Vogler, 2016: p. 2) The assumption of this negative response is that the earth is our common home. As St Francis puts it, "there has been a growing conviction that our planet is a homeland and that humanity is one people living in a common home." (Pope Francis, 2015: p. 121)

Global governance has actually been proposed as vital for the long-running attempt to create a comprehensive and effective international climate regime. From the outset this has been widely, but not universally, recognised as something of critical importance for planetary survival and has been accorded a political status which marks it out from more mundane environmental issue areas. Conferences of the Parties (COPs) to the United Nations Framework Convention on Climate Change (UNFCCC) have been attended at the highest political level by presidents and prime ministers. United Nations (UN) Secretaries General have summoned them to take action and climate change issues have appeared on the agenda of the Security Council, Group of 8 (G8) and, indeed, most other leading international organizations (Vogler, 2016: p. 1).

The concept of global governance is generally based on two key concepts: mitigation and adaptation. Although they are conceptually and completely different, they tend to be treated together (Morel, 2019: p. 1). They differ in the sense that mitigation is a collective effort of all nations to control the atmospheric content of greenhouse gases (GHG), whereas adaptation refers to the steps each country takes individually to mitigate the effects of climate change. Policies of mitigation usually include conferences of the parties and inter-State networks. 
Mitigation is an instantiation of the problem of the management of the commons. Here, it is through multilateral international agreements.

Adaptation differs from mitigation in that it is the area where actions to reduce the impact from climate change take place. Adaptation refers to 'actions targeted at a specific vulnerable system, in response to actual or expected climate change, with the objective to either limit negative impacts or exploit positive ones'. It involves establishing the vulnerability of the systems to any changes, and determining the risk in order to ensure appropriate long-term management responses which can be put in place (Carter, 2019: pp. 71-72). Each nation has an interest in what other nations do in mitigation as it potentially affects them.

Adaptation is ultimately a national problem, and in most cases what individual nations do does not affect the other nations. The fact that there is an overlap between adaptation and mitigation, in the sense that some mitigation measures can contribute to adaptation or vice versa, does not change the fundamental difference between the two. It should be noted that adaptation is not a response as such since it does not aim at changing the situation but aims at living with it. As it has been rightly pointed out, "Some climate change is already inevitable, so we will need to adapt. Much adaptation will take place without any policy action as people and firms adjust to changing circumstances" (OECD, 2015: p. 64). If mitigation calls for mechanisms of action, adaptation on the contrary, calls for mechanisms of resilience (Kengoum, 2013: p. 6).

So far, we have been exploring the functioning of the collective action approach. We are now turning to some of its main challenges.

\subsection{Some Problems with the Collective Action Approach}

The Copenhagen Summit in 2009 and indeed all other climate summits have shown signs that many problems arise when collective actions in climate change are undertaken (Hadden, 2015). In this section, we examine some of these problems.

The first problem with the global response is that it is very abstract since it clearly puts the burden of the responsibility on organizations instead of the individual. The assumption here is that the group is an extension of the individual, which is not the case. As it has been clearly noticed by Mancur Olson (Olson, 1978), groups are always different and dependent on individuals. There is nothing like a group conscience. Making this mistake, many global responses assume the existence of class conscience, in the Marxist use of the term, without recognising any possibility of disagreement between members of a community. In this line, there has always been an opposition between rich and poor countries, within poor countries, between those who are richer than others and among rich countries. According to Marx, the history of industrialised countries is that of the conflict between two groups' interests, those of the rich against those of the poor (Olson, 1978: p. 13). It is not surprising, therefore, that environmental ethics has often had an ideological tone. Many of the poor countries take it to be 
part of strategies developed by the rich to slow down their process of development. But if it is established that there are only individuals' interests that at some particular time may coincide, this opposition that we have in environmental ethics can be overcome. Contractualists have always insisted on the fact that the human being is deeply egoistic and indifferent to others. It is only when they face a challenge above them that their interests coincide. Rousseau, for instance, thought that the savage was a noble. Unfortunately, adherents of collective action in environmental ethics seem to neglect this aspect and accordingly, fail to tell the individual that his interest is also in play in case he does not act.

Directly linked to this, a further problem with the collective action paradigm is that, since it relies not on individuals but on groups, it does not successfully answer the challenge of groups' interests. In fact, when individuals become members of groups, it becomes difficult to see something else apart from the group's interest. This leads to a clearly partisan understanding of the issue at stake, in such a way that it becomes impossible to clearly focus on the common concern. Mancur Olson has underlined the fact that individuals' interests are generally relegated to the second plan when groups interests are on the balance (Olson, 1978: p. 26). This clearly shows that if environmental ethics continues to be the issue of groups whose interests oppose each other, then the result is likely going to be a continual shift from the main issue (protecting our common home) to the groups desires.

Another problem which is related to the previous points is the fact that since environmental ethics has been presented as a group issue, many members of the community are not clearly given enough information about what the real impact of their actions is on the environment. This is what we may call the expert assumption, the assumption that to understand environmental changes due to human action, we must be experts. Environmental ethics has often been considered as a super hero play in which Heads of State are the heroes and other citizens the spectators. By making environmental ethics a more common concern, it is clear that common citizens will feel more involved and will then be ready to do more. Unfortunately, many of those experts have difficulties saying in simple words not only what is going on and what we should do. There is no clear democratization of the struggle against environmental deterioration; this might explain the indifference we observe from ordinary people. This indifference is easily understandable if we consider the fact that giving enough information to individuals about the situation they face and the impact their action can have in affecting that situation has been proved successful in initiating action (Singer, 2010). In this line, we should regret that the outcomes of the different summits are hardly objects of continuous publicity as we might expect on such an important issue.

From what has been said in this section, the collective action paradigm in environmental ethics faces three main challenges: it fails to remove the ideological orientation of environmental ethics which in turn is responsible for the devel- 
opment of partisan interpretation of environmental ethics and it fails to make individuals more responsible by presenting environmental ethics as a matter of expertise. We therefore need to explore more deeply how an individual response to environmental crises can be properly worked out.

\section{The Individual as a Response to Environmental Crises}

In this section, we will examine three responses to environmental crises that make an appeal to individuals. After pointing at some of the shortcomings of the first two views, we shall see how that of Wittgenstein has proved more satisfactory.

\subsection{The Response of Outstanding Individuals}

An appeal to individuals has been recently explored through a look at the works of outstanding individuals in international organisations such as the United Nations. This type of response highlights how international civil servants play a crucial role in initiating processes of legal and institutional change in the UN system (Bode, 2015). The UN functions on the basis of ideas which are suggested by some of its members. These individuals are experts in their respective fields since many of them have worked for years on such questions before gaining the position they have in the organisation. In this context, these individuals are the missing creative elements that the organisation needs to initiate and spread ideas (Bode, 2015: p. 1). A main characteristic of this approach, which is clearly advantageous, is that it is not monopolistic. This can be easily understood by seeing that the individuals under consideration come from three main groups: the intergovernmental arena with its state representatives; the professional secretariat and its international civil servants; and the non-governmental organizations (NGOs), external experts, academics, independent commissions and other individuals who regularly engage with the UN (Bode, 2015: p. 2).

However, this approach has its shortcomings. First of all, it is mainly idealistic because the United Nations has no direct coercive means if not through the Security Council (SC). But members of the SC are resistant in tackling questions of environmental ethics since many of these members are not examples as far as greenhouse gas control is concerned. This is to say that though individuals might have good positions at top levels, the way they can help in changing the situation in environmental matters is far from being direct. Besides, the number of such individuals is so small that it is difficult to see how they can carry on their shoulder such a great responsibility and address the problem efficiently.

\subsection{The Appeal to the Individual's Recognition of the Intrinsic Value in Things}

Another response that calls on the individual is based on the theory of intrinsic value. In philosophy, the theory of intrinsic value is mostly due to the German philosopher Immanuel Kant (1724-1804) who defended the view that we should 
not treat other human beings as means for other purposes but as ends in themselves. At the level of human ethics, the theory of intrinsic value calls for a shift from our egoistic nature to a more altruistic one. In environmental philosophy, this response calls for a transition from anthropocentrism to biocentrism: we should not treat other creatures as means but as ends in themselves (Sarkar, 2005).

The problem with this approach is that intrinsic value is not well defined because to its adherents, it either means not related to other things or not instrumental to man. Besides, the non-instrumentality of other creatures can be explained otherwise than their intrinsic value. The theory of intrinsic value, we may say, forces the individual to a kind of environmental realism that many do not accept. In fact, many people contend that ethics does not exist in the environment. If anything has a certain value, it is only relatively as it serves our purpose.

As we shall now see, Wittgenstein's view does not espouse the intrinsic value theory for at least two reasons. On the one hand, all beings are related or interdependent in a way or another. On the other hand, these beings are not ends in themselves for there is always something superior to them; creatures, including human beings, are not ends in themselves.

\subsection{Wittgenstein's Ethical Individualism}

As we have seen above $(\$ 1)$, to many people, Wittgenstein's ethics is clearly pragmatic and utilitarist. For recall, in the first phase of his philosophy which he developed in the Tractatus Logico-philosophicus, Wittgenstein clearly rejected psychologism by advocating a kind of correspondence theory of truth. Accordingly, he established a hierarchy of meaningful propositions in which the propositions of science are on top due to their contingent nature, the propositions of logic in the middle due to their tautologous nature and the propositions of ethics, aesthetics and metaphysics at the bottom, due to their failure in having a clear reference. Ethical discourse has thus been classified in the realm of nonsensical discourse. Wittgenstein faced the challenge of explaining the value of ethics despite its nonsensicality. It is in order to respond to this challenge, they say, that he has brought ethics back, in the context of his pragmatic turn.

Wittgenstein's ethics is, this interpretation admits, clearly in accordance with pragmatism because the second phase of his philosophy which he develops in the Philosophical Investigations echoes some of the main themes of pragmatism namely "language as use" and "relativity of truth". In this text, some authors think (Mondoué \& Nguemeta, 2014: pp. 115-116), Wittgenstein has overcome the mystery of ethics and has succeeded in expressing it through different ways of using the term ethics. Following this line, not only truth is relative, ethics too is relative to a culture.

But it should be clear that Wittgenstein's ethics does not follow from his epistemological pragmatism. There are two reasons for this: 
Firstly, Wittgenstein rejects solipsism in the linguistic field (Chauviré, 2009) but accepts it in ethics. He says in the Notebooks that "I can only make myself independent of the world-and so in a certain sense master it-by renouncing any influence on happenings" and the desire to influence the happenings of the world is evil (Wittgenstein, Notebooks 1914-1916 [1961], 1998b, p. 77). With the second Wittgenstein, truth depends, for sure, on the community and the user's competence in using a language. This is appreciated relative to his successful application of the rules used in his community. But the same does not go with ethical truth. Ethical truth does not depend on the community since there are no human models in ethics (Schönbaumsfeld, 2007). Ethical truth depends on the connexion between the individual and the world. Of course the individual can choose not to connect to the world for a reason or another; this is his choice.

Secondly, Wittgenstein's ethics is not hedonistic. Contrary to some interpretations (Fornès, 2017), Wittgenstein's ethics does not see the individual as an interest "maximiser." In the Philosophical Grammar, he defines pragmatism as a doctrine which seeks to fulfil an individuals' interest: "I don't call an argument a good argument just because it has the consequences I want (Pragmatism)" (Wittgenstein, 1974a: p. 185). As it has been clearly pointed out by the Holy Father Francis, a hedonist ethics is incompatible with ecological conversion. This is so because ecological conversion is conditioned by the development of good aesthetical sense. It is only through this aesthetical sense that the world can truly be contemplated. A similar view is developed by Wittgenstein (Wittgenstein, 1974b: $\$ 6.45$ ) with his identification of ethics to aesthetics. So if ethics is conditioned by the contemplation of the world and if the contemplation of the world is antithetic to utilitarian considerations, we must conclude that Wittgenstein's ethics is antithetic to utilitarian/pragmatic considerations.

Besides, a pragmatic interpretation of Wittgenstein's ethics would be unable to explain Wittgenstein's insistence that ethics is not found in the world. If ethics is relative to the culture, then it is found in the world. But according to Wittgenstein, ethics is not found in the world. It follows then that ethics is not relative to the culture. And if ethics is not relative to a culture, it must have something which is superior to human beings. It is because ethics is above us that Wittgenstein explains the non-instrumentality of the world not by a kind of weak anthropocentrism or biocentrism, but by a kind of the individual's connection to the world. According to this kind of good design argument, the world is an organized system, in such a way that touching one element will mean destroying the harmony of the world.

From these elements, Wittgenstein's ethics has clearly been cleared from its pragmatic clothing. But how does his real ethics look like?

Wittgenstein summarizes his ethics thus: "What is Good is Divine too. That, strangely enough, sums up my ethics." (Wittgenstein, 1998a: p. 5) If this short sentence sums up Wittgenstein's ethics, then understanding it might be sufficient to get the real picture of his ethics. 
The sentence seeks to define the good in terms of the divine. But what is the divine? Wittgenstein says, "The meaning of life, i.e. the meaning of the world, we can call God." (Wittgenstein, 1998b: p. 73) And he adds that to understand the meaning of the world is to believe in God which in turn means to "to see that the facts of the world are not the end of the matter" (Ibid., p. 74). Properly understood, Wittgenstein seems to indicate here that ethics begins with the rejection of materialism and, epistemologically, with the rejection of positivism. It is at this level that the rejection of utilitarianism becomes clearer. As the author suggests, "However this may be, at any rate we are in a certain sense dependent, and what we are dependent on we can call God." (Id.) This time around, God does not only mean the "meaning of the world" but the world itself. As Wittgenstein points out, "In this sense God would simply be fate, or, what is the same thing: The world" (Id.)

This view creates and interdependence between the human being and the world, that is between the human being every other creatures for as we can see from the Tractatus, "the world is everything that is the case" (\$\$1, 1.2 and 2). One can now see why Wittgenstein's ethics is clearly ecological. Since the world is everything that is the case and since we are somehow dependent on the world, then we are dependent on everything that exist. This simply means that everything that is the case should be preserved in order for us to remain in harmony with other things which cannot be destroyed without affecting us in a certain way. It is at this level that aesthetics plays a key role in Wittgenstein's ethics. Not only are we dependent on the world, but also the world is to be contemplated because it strikes us as something we do not understand. The mystical fact, says Wittgenstein, is not in the way the world is, but the fact that there is a world (Wittgenstein, 1974b: \$6.44) that this world transcends us. But how does this relate to the individual?

The answer to the above question should be found in the way Wittgenstein thinks we can aesthetically appreciate the world. The world is not limited, but our appreciation of the world is necessarily limited (Wittgenstein, 1974b: \$6.45). Due to our internal limitedness, we should renounce changing the world or, what is the same, we should struggle with ourselves, with our desires, to leave the world as it is. This becomes obvious when we consider Wittgenstein's view that only our will is good or bad. This is an aspect of Wittgenstein's ethics which has not often been clearly stated by commentators. It has not often been noticed that preserving something means leaving it as it is. It is of the utmost importance, we think, to recognize that the greatest action in Wittgenstein's sense of the word consists in renouncing to act. Renouncing to unnecessary actions, that is what Wittgenstein's ethics teaches: "I can only make myself independent of the worldand so in a certain sense master it-by renouncing any influence on happenings." (Wittgenstein, 1998b: p. 73).

It should now be clear why we have said that Wittgenstein's ethics is individualistic. Working on one's character so as to avoid excesses in our desires is the 
key against environmental deterioration. Many of the actions we carry out that destroy the environment are not necessary. The proof is that when individuals are forced to reduce the rate of their environmental impact through taxation for instance, they begin reducing their standard of living quantitatively but not necessarily qualitatively. It should not be surprising that the most polluting countries are those that have many industries that is, countries in which massive consumption is normal and moderation abnormal.

\section{The Relevance of Wittgenstein's View: The Individual as a Response to Environmental Crisis Today}

We wish to end this paper by insisting on the way the individual action paradigm is now worked out. This might help to see more deeply that the individual action option is not completely awkward. If we take note of the developments that have been going on in the UNESCO and in the Catholic Church, we will easily confirm that the individual action paradigm is slowly being recognized as a reliable alternative approach in environmental ethics.

\subsection{The Appeal to Individuals in the Environmental Education Unit of the UNESCO}

Since 1983 the UNESCO has created a full Environmental Education Unit (EEU) under the United Nations Environment Programme (UNEP) so as to train trainers on environmental issues and promote the inclusion of environmental concerns in the curricula of different States (Hungerford, 1994). This approach generically termed "environmental issue instruction", attempts to educate future citizens in the craft of making informed personal and social decisions in their lives. Its fundamental assumption is the following: "If we want to develop large numbers of learners who are skilled and dedicated environmental citizens, the learners must feel a sense of ownership toward the issues needing resolution and a sense of empowerment with respect to helping with that resolution." (Ibid., p. v)

One key element that should be noted at this level is the importance of the interaction between learners and the environment. As it is recognised by the UNESCO EEU, "It is not sufficient to 'tell students about ecology, or to present them with an awareness that environmental issues exist. Students must experience an EE curriculum which allows them to discover how they interact with the environment themselves and to assess their own impact on the environment." (Ibid., p. vi) For this purpose the EEU proposes the effective use of fieldtrips method in school as well as inventorying and using the community resources. In this vein, year one of the curriculum in environmental ethics is entirely dedicated to ecology (Hungerford, 1994: pp. 32-58). During the first year, the curriculum focuses on two key components: 1) the ecosystems and 2) the human impact on the ecosystems. During the second year, the link is established between the environment health and the human health. This link between the 
quality of the environment and the quality of life is more deeply explored during the third year with an emphasis on the actions the individual can take to remedy environmental degradation.

This curriculum, if implemented, could be a valuable tool in environmental ethics. We are not losing hope, given that the green school concept is now becoming familiar to Africa (visit for instance the website https://greenafrica.ngo/projects/ green-school-programs/).

\subsection{The Appeal to Individuals in Christian Ethics: The Case of the Pope Francis}

Another point that shows the relevance of Wittgenstein's view can be found in the Christian ethics. Christian ethics as it is expressed in Pope Francis' Encyclical Letter (Pope Francis, 2015) is indeed very similar to Wittgenstein's view in many respects.

Firstly, Christian ethics and Wittgenstein recognise that ethics is vertical. In other words, ethics is not primarily concerned with our actions towards our fellow humans. Wittgenstein clearly points the fact that ethics is not found in the world; it is transcendental. In a now classical division between meaningful, meaningless and nonsensical propositions in the Tractatus Logico-philosophicus $\$ 5.525$, he classifies ethical propositions as nonsensical propositions for the reason that they purport to have a reference, to be found in the world, but fail to do so. Ethics is beyond the world. In the same way, Pope Benedict XVI called for the recognition of a higher order above us. There is a verticality in ethics that, once forgotten, is responsible for the present moral decline we observe (Pope Francis, 2015: p. 7). In the same line St Francis Assisi thinks that integral ecology transcends the limits of language of mathematics and biology (Pope Francis, 2015: p. 10). The importance of acknowledging the verticality of ethics might be directly seen if we consider the ideological savour of environmental ethics which we have described earlier. If ethics is horizontal or ethical actions appreciated only according to human standards, then there is no assurance that those who tell us that we should protect the environment are not doing so for their own interest. Contrary to this, if what we are supposed to do is received from our creator, then there is an assurance of impartiality for God by definition cannot prefer some human beings to others.

Secondly, Christian ethics sees a clear cut distinction between caring for the environment and being utilitarian. It would be useful here to recall two important points. On the one hand, that Wittgenstein's pragmatism does not apply to his ethics. On the other hand, that there is a close relationship of ethics to aesthetics in Wittgenstein thought. In $\$ 6.421$ of his Tractatus Logico-philosophicus, he says insistently that ethics and aesthetics are one and the same thing. To be a pragmatic in ethics also means to be a utilitarian, in such a way that we only see things around us as far as they are useful to us. It is only when we are able to see things irrespective of their use to us that real environmental ethics is possible. 
Pope Francis acknowledges this fact in the following words:

The relationship between a good aesthetic education and the maintenance of a healthy environment cannot be overlooked. By learning to see and appreciate beauty, we learn to reject self-interested pragmatism. If someone has not learned to stop and admire something beautiful, we should not be surprised if he or she treats everything as an object to be used and abused without scruple. (Pope Francis, 2015: p. 157)

The consequence of this aesthetic turn in environmental ethics is a call for change in lifestyles, that which Pope Francis calls a global ecological conversion.

Lastly and perhaps more importantly, Christian ethics recognizes an interconnection between the different beings that constitute the cosmos. There is a connection between man and God, man and man, and man and the earth. According to the Bible, these three relationships are vital and contribute to the harmony of the universe. "Everything is related, and we human beings are united as brothers and sisters on a wonderful pilgrimage, woven together by the love God has for each of his creatures and which also unites us in fond affection with brother sun, sister moon, brother river and mother earth" (Pope Francis, 2015: p. 68). Breaking up these relationships in any ways is a sin. It should thus be noted that according to this view, not taking care of the earth is just as punishable as not being good with our neighbours or not behaving according to the Ten Commandments. Simply put, Christian ethics considers that each individual is responsible for the caring of our common home: "till it and keep it" (Gen 2:15). As Pope Francis points out, the harmony between the Creator, humanity and creation as a whole was disrupted by our presuming to take the place of God and refusing to acknowledge our creaturely limitations. This in turn distorted our mandate to "have dominion" over the earth (cf. Gen 1:28). As a result, the originally harmonious relationship between human beings and nature became conflictual (Pope Francis, 2015: p. 48). This view is similar to Wittgenstein recognition of our limited view of the world. In $\$ 5.6331$ of the Tractatus logico-philosophicus, he takes the image of an eye which sees the world. The purpose of this image is to show that our view of the world is necessarily limited; the eye that sees the world cannot see itself. "The world is my world", he says in \$.5.62. This aspect-seeing conception of the world is also echoed in Pope Francis' Encyclical. In his words, "Just as the different aspects of the planet-physical, chemical and biological -are interrelated, so too living species are part of a network which we will never fully explore and understand." (Pope Francis, 2015: p. 103) This aspect-seeing conception common both to Wittgenstein and Pope Francis is not necessarily bad news. It helps to understand that each individual, wherever he finds himself is responsible for the part of the earth around him.

\section{Conclusion}

We hope this paper will help in considering the individual as an important variable in solving environmental problems. In this line, we will like to end by pro- 
posing the following:

1) The individual's responsibility in tackling environmental problems should be emphasised. In this line, scientists should communicate more regularly and less technically on environmental issues in order to give the individual adequate information as far as the degradation of the earth is concerned so as to measure the real impact. This is because individuals are prompt to act only when they are directly concerned with a situation.

2) The individual should be addressed as the person on whom we count to solve the problem. His responsibility in caring for the environment should be taken seriously by indicating to him the importance of nature and the way he can help future generations by preserving the small resources he has at his disposal.

3) The school curriculum should include students' participation in caring for the environment as part of a long-term evaluation. Each student could plant a tree and follow up its growth over the long term of his education in the secondary school. He could also choose a domestic animal which he will take care of. The evaluation is done at the end of each school term so as to see if the animal is alive and is well treated. He could also choose a portion of his community outside of the family compound or in the school premise which he will systematically clean a definite number of times per week. The school system should find ways of reinforcing good environmental culture in students so that they become more conscious of the role they play as individuals in protecting the environment. But since no change in lifestyle is easy, there should be constraints on individuals so that he who fails to do his part of the job should be sanctioned by the school system. A new culture of low consumption should be cultivated at an early age in primary school so as to help young learners quickly understand how too much consumption can lead to general chaos.

4) Since schools are not the only place where individuals' consciences can be easily touched, it is important that other social stake holders do the same. The Church should include environmental courses the curricula of Seminaries and houses of formation so as to make the future priest and religious more acquainted with sensitizing people on such issues.

5) Each individual reading this paper, no matter his position, should act at his level so as to let other people know that they can help to protect our common home.

\section{Conflicts of Interest}

The authors declare no conflicts of interest regarding the publication of this paper.

\section{References}

Bode, I. (2015). Individual Agency and Policy Change at the United Nations: The People of the United Nations. New York: Routledge. https://doi.org/10.4324/9781315751436

Campagna, C., \& Guevara D. (2020). Evaluating Climate Change with the Language of 
the Forms of Life. In G. Henning Brian, \& W. Zack (Eds.), Climate Change Ethics and the Non-Human World (pp. 75-89). London: Routledge. https://doi.org/10.4324/9780429356988-7

Carter, L. (2019). Indigenous Pacific Approaches to Climate Change: Aotearoa/New Zealand. Cham: Palgrave Macmillan. https://doi.org/10.1007/978-3-319-96439-3

Chauviré, C. (2009). L'immanence de l'ego: Langage et subjectivité chez Wittgenstein. Paris: PUF. https://doi.org/10.3917/cite.038.0025

Fornès, A. (2017). Sens et éthique: Au cour du discours, "Wittgenstein à l'hôpital”. Nice: Université Côte D’Azur.

Hadden, J. (2015). Networks in Contention: The Divisive Politics of Climate Change. New York: Cambridge University Press. https://doi.org/10.1017/CBO9781316105542

Hungerford, H. (1994). A Prototype Environmental Education Curriculum for the Middle School (Revised). UNESCO.

Kengoum, F. (2013). Adaptation and Mitigation Policies in Cameroon: Pathways to Synergy. Bogor: CIFOR.

Mondoué, R., \& Nguemeta, P. (2014). Vérificationnisme et Falsificationnisme, Wittgenstein vainqueur de Popper? Paris: L'Harmattan.

Morel, B. (2019). Real Option Analysis and Climate Change: A New Framework for Environmental Policy Analysis. Cham: Springer Nature Switzerland AG. https://doi.org/10.1007/978-3-030-12061-0

OECD (2015). Cool Policy: Climate Change Mitigation Supporting Growth. OECD Economic Outlook, 2015, 59-80. https://doi.org/10.1787/eco outlook-v2015-2-3-en

Olson, M. (1978). Logique de l'action collective (M. Levi, Trans.). Paris: PUF.

Peeters, W. E. (2015). Climate Change and Individual Responsibility: Agency, Moral Disengagement and the Motivational Gap. Hampshire: Palgrave Macmillan.

Peters, M. (2020). Wittgenstein and the Ethics of Suicide: Homosexuality and Jewish Self-Hatred in Fin de siècle Vienna. In M. Peters (Ed.), An Educational Philosophy and Theory Reader Volume VIII: Wittgenstein, Anti-Foundationalism, Technoscience and Philosophy of Education (pp. 65-79). London: Routledge. https://doi.org/10.4324/9781003017035-4

Pope Francis (2015). Laudato Si: On Care for Our Comon Home [Encyclical].

Sarkar, S. (2005). Biodiversity and Environmental Philosophy: An Introduction. Cambridge: Cambridge University Press. https://doi.org/10.1017/CBO9780511498558

Sarratt, N. (2012). Ecological Forms of Life: Wittgenstein and Ecolinguistics. Denton, TX: University of North Texas.

Schönbaumsfeld, G. (2007). A Confusion of the Spheres, Kierkegaard and Wittgenstein on Philosophy and Religion. Oxford: Oxford University Press. https://doi.org/10.1093/acprof:oso/9780199229826.001.0001

Singer, P. (2010). The Life You Can Save, How to Do Your Part to End World Poverty. New York: Random House Trade Paperbacks.

Søndergaard Christensen, A.-M. (2019). Boundless Nature: Virtue Ethics, Wittgenstein and Unrestricted Naturalism. In D. M. Benjamin, \& K. Oskari (Eds.), Ethics in the Wake of Wittgenstein (pp. 63-83). New York: Routledge.

https://doi.org/10.4324/9781315181172-4

Taylor, C. (2019). Our Fellow Creatures. In D. M. Benjamin, \& K. Oskari (Eds.), Ethics in the Wake of Wittgenstein (pp. 220-232). New York: Routledge.

https://doi.org/10.4324/9781315181172-11 
Vogler, J. (2016). Climate Change in World Politics. New York: Palgrave Macmillan. https://doi.org/10.1057/9781137273413

Wittgenstein, L. (1974a). Philosophical Grammar (R. Rhees, Ed., \& A. Kenny, Trans.) Oxford: Basil Blackwell.

Wittgenstein, L. (1974b). Tractatus Logico-Philosophicus [1922] (D. F. McGuinness, Trans.). London: Routledge.

Wittgenstein, L. (1998a). Culture and Value, A Selection from the Posthumous Remains (G. V. Wright, Ed., \& P. Winch, Trans.). Oxford: Blackwell Publishers Ltd.

Wittgenstein, L. (1998b). Notebooks 1914-1916 [1961] (2nd ed., V. W. M., Ed., \& G. E. Anscombe, Trans.) Oxford: Blackwell Publishers. 